\title{
CARACTERIZAÇÃO CARIOLÓGICA DE PALMEIRAS DO GÊNERO Butia (Arecaceae) ${ }^{1}$
}

\author{
LAUÍS BRISOLARA CORRÊA ${ }^{2}$, ROSA LÍA BARBIERI ${ }^{3}$, MARCELO ROSSATO ${ }^{4}$, \\ MIRIAM VALLI BÜTTOW ${ }^{5}$, GUSTAVO HEIDEN ${ }^{6}$
}

RESUMO - O butiá é um fruto nativo muito consumido no Sul do País, sendo comum encontrá-lo como frutífera cultivada. No Rio Grande do Sul, ocorrem cinco espécies de palmeiras deste gênero. O número cromossômico de Butia eriospatha e de B. odorata é descrito pela primeira vez. B. capitata e B. yatay tiveram seu número cromossômico descrito anteriormente, apesar de seu cariótipo nunca ter sido reportado antes, e $B$. paraguayensis não concordou com a contagem anterior. Este trabalho teve como objetivo analisar as características cromossômicas dentro e entre cinco espécies deste gênero, sendo nove exemplares de B. capitata, três de B. eriospatha, três de B. odorata, dois de B. paraguayensis e dois de B. yatay. Foram coletados frutos de populações naturais, cujas sementes foram colocadas para germinar. Os meristemas apicais radiculares das plântulas foram submetidos aos pré-tratamentos 8 -hidroxiquinoleína $0,002 \mathrm{M}$, água a $0^{\circ} \mathrm{C}$ e colchicina $1 \%$, sendo fixadas em solução fresca de etanol e ácido acético glacial 3:1 (v/v) e coradas em solução Giemsa 2\%. Todas as espécies estudadas apresentam o mesmo número cromossômico, $2 n=2 x=32$, possuindo também a mesma fórmula cariotípica: 14 cromossomos metacêntricos, 12 submetacêntricos e 6 acrocêntricos. Os cariótipos de todas as espécies são simétricos, apresentando dois pares de cromossomos satelitados, um par de cromossomos metacêntricos satelitados e um par de acrocêntricos também satelitados.

Termos de indexação: cariótipo, número cromossômico, Palmae, butiá.

\section{KARYOLOGICAL CHARACTERIZATION OF Butia (Arecaceae) PALM TREES}

ABSTRACT - Butiá is a native fruit which is a lot used in the Southern of Brazil and it is usually harvested like crop fruit. Five species of native palm trees of the genus Butia occur in Rio Grande do Sul state, Brazil. Chromosome numbers and karyotype of Butia eriospatha and B. odorata are being reported for the first time. B. capitata and B. yatay had the chromosome numbers previously described, although its karyotype has never been reported before and B. paraguayensis coincided not with the early count. Fruits from natural populations were collected; the seeds were extracted and put to germinate. The aim of this paper was to analyze the chromosomical features between and into five species of this genus. Nine specimens of B. capitata, three of $B$. eriospatha, three of $B$. odorata, two of $B$. paraguayensis and two of $B$. yatay were analyzed. Root tips from seedlings were pretreated in $0.002 \mathrm{M} 8$-hydroxyquinoline or icy water $\left(0^{\circ} \mathrm{C}\right)$ or $1 \%$ colchicine, fixed in ethanol and acetic acid (3:1) and then stained in $2 \%$ Giemsa. All species showed the same chromosome number, $2 \mathrm{n}=2 \mathrm{x}=32$, and the same chromosome morphology: 14 metacentric, 12 submetacentric and 6 acrocentric chromosomes. Karyotypes of all species are symetric, with two pairs of sattelite, one pair of metacentric and one pair of acrocentric chromosomes.

Index terms: karyotype, chromosome numbers, Palmae, pindo palm.

'(Trabalho 232-08). Recebido em: 08-09-2008. Aceito para publicação em: 03-04-2009.

${ }^{2}$ Mestrando em Genética e Biologia Molecular, Universidade Federal do Rio Grande do Sul (UFRGS), Porto Alegre-RS, lauisbrisolara@gmail.com

${ }^{3}$ Dra. em Genética e Biologia Molecular, Embrapa Clima Temperado, Pelotas-RS, lia.barbieri@gmail.com

${ }^{4}$ Dr. em Agronomia, Universidade de Caxias do Sul, Caxias do Sul-RS, mrossato@ucs.edu.br

${ }^{5}$ Doutoranda em Genética e Biologia Molecular, UFRGS, Porto Alegre-RS, miriamvb@gmail.com

${ }^{6}$ Mestre em Biologia Vegetal, Jardim Botânico do Rio de Janeiro, Rio de Janeiro-RJ, gustavo.heiden@gmail.com 


\section{INTRODUÇÃO}

Arecaceae ou família das palmeiras é um grupo botânico complexo, que forma um dos principais troncos evolutivos das monocotiledôneas, possuindo distribuição pan-tropical, com algumas espécies adaptadas a climas mais frios (Dransfield \& Uhl, 1987). A classificação taxonômica desta família abrange 2.361 espécies dentro de 189 gêneros (Angiosperm Phylogeny Website, 2008). Esta classificação é tradicionalmente baseada nas características morfológicas dos troncos, das folhas, dos frutos e das flores, nas particularidades anatômicas de seus órgãos, em comparação com características citológicas e histológicas, incluindo caracteres descritivos dos grãos de pólen, estudos de distribuições geográficas atuais e a história evolutiva da família e de seus gêneros (Dransfield \& Uhl, 1987; Henderson et al., 1995).

No Rio Grande do Sul, ocorrem seis gêneros de palmeiras nativas: Bactris, Butia, Euterpe, Geonoma, Syagrus e Trithrinax. Cada gênero ocupa um ecossistema específico, e com exceção das palmeiras que habitam a Mata Atlântica sensu stricto (Floresta Ombrófila Densa), dificilmente há interação entre estas espécies. Butia, Euterpe e Syagrus são os gêneros mais representativos, principalmente devido à sua distribuição geográfica e importância econômica. Bactris, Euterpe e Geonoma são restritos à Mata Atlântica (Rossato, 2007).

O gênero Butia (Becc.) Becc. pertence à subtribo Butiinae, sendo amplamente distribuído no Brasil (Sul, com algumas espécies ocorrendo no Centro-Oeste e Sudeste), Paraguai, Argentina e Uruguai. É caracterizado por plantas monoicas, protândricas e alógamas, que se desenvolvem bem ao sol ou em locais pouco sombreados, estando presentes em diferentes ambientes, desde campo aberto até vegetação de restinga, ou associados à mata de araucária. No Estado do Rio Grande do Sul, é registrada a ocorrência de B. capitata (Mart.) Becc., B. odorata (Barb. Rodr.) Noblick ex Marcato, $B$. eriospatha (Mart. ex Drude) Becc., B. paraguayensis (Barb. Rodr.) L. H. Bailey e B. yatay (Mart.) Becc (Marcato, 2004; Rossato, 2007).

No gênero, a espécie $B$. capitata está entre as de maior valor potencial reconhecido, sendo incorporada em programas de desenvolvimento sustentável de frutíferas (PNDU, 2007) e de interesse para o melhoramento genético (Clement, 2001).

Marcato (2004) descreve a ocorrência de 11 espécies em zonas subtropicais, com centros de diversificação na América Latina e ocorrência natural em zonas subtropicais e tropicais, sendo atualmente cultivadas em diversos continentes.

Apesar de serem bastante conhecidas e exploradas para consumo de frutos e em paisagismo, há uma grande carência de informações científicas sobre estas espécies. O gênero Butia está sofrendo uma série de interferências antrópicas, absorvendo este impacto de tal forma a ser considerado em risco de extinção em áreas naturais (Rivas \& Barilani, 2004).

Informações cariológicas sobre a maioria das palmeiras são geralmente restritas a números cromossômicos (Röser, 1994). Os estudos de Read (1965, 1966) contribuíram muito para o conhecimento do número cromossômico em palmeiras; além disso, seus trabalhos corrigiram muitas contagens equivocadas realizadas anteriormente. Contudo, o trabalho mais representativo sobre citogenética de Arecaceae foi o de Röser (1994), que descreveu cariologicamente 56 taxa, sendo que, destes, 11 gêneros e 17 espécies tiveram seu número cromossômico reportado pela primeira vez. Além disso, este autor também caracterizou regiões específicas do DNA de várias espécies, através de bandeamentos moleculares, C-Giemsa e NOR.

De acordo com Goldblatt (1980), o gênero Butia possui $\mathrm{n}=\mathrm{x}=16$, reportando também $\mathrm{n}=8$ para B. paraguayensis, entretanto deixou explícita a necessidade de maiores estudos para confirmação desses resultados. Com isso, Gaiero \& Mazzella (2005) foram mais conclusivos em seus resultados, descrevendo os números cromossômicos de B. yatay, B. capitata e Syagrus romanzoffiana como $2 \mathrm{n}=32$, além de Trithrinax campestris, que apresentou $2 \mathrm{n}=$ 36 cromossomos.

Diante da existência de poucos estudos citogenéticos na maioria das espécies de Butia, este trabalho teve como objetivo analisar as características cromossômicas dentro e entre cinco espécies deste gênero.

\section{MATERIAL E MÉTODOS}

Foram coletados frutos de indivíduos de $B$. capitata, B. eriospatha, B. odorata, B. paraguayensis e B. yatay no Rio Grande do Sul, em populações naturais. Exsicatas dos espécimes foram depositadas no herbário da Universidade de Caxias do Sul (HUCS) (Tabela 1). As sementes foram colocadas para germinar em substrato composto por solo humoso e areia 3:1 (v/v), em recipientes plásticos, mantidos em casa de vegetação, segundo tratamento de superação de dormência descrito por Rossato (2007). Foram analisados nove exemplares de B. capitata, 
três de $B$. eriospatha, três de $B$. odorata, dois de $B$. paraguayensis e dois de B. yatay (Tabela 1).

Seis meses após a germinação, as plantas foram tratadas semanalmente com solução $(1 \mathrm{~g} / \mathrm{l}) \mathrm{de}$ formulado 18-18-18 (N-P-K) acrescido de micronutrientes e $25 \mu \mathrm{l} / 1$ de solução-estoque de ácido indolbutílico 1.000 ppm (Singh, 1961). Foram coletados ápices de raízes sadias com aproximadamente $1 \mathrm{a}$ $1,5 \mathrm{~cm}$ de comprimento e que demonstravam boas condições de crescimento. Após a coleta de raízes, as plantas foram transplantadas para o campo e cadastradas no acervo do Banco Ativo de Germoplasma de Frutíferas Nativas da Embrapa Clima Temperado.

Para o pré-tratamento das pontas de raízes, foram testados 8 -hidroxiquinoleína $0,002 \mathrm{M}$, água gelada a $0^{\circ} \mathrm{C}$ e colchicina a $1 \%$. Para 8 -hidroxiquinoleína $0,002 \mathrm{M}$, foram testados os tempos de exposição por $10 ; 20 ; 27 \mathrm{e} 48$ horas, à temperatura de $18^{\circ} \mathrm{C}$, e por 9,18 e 25 horas, em temperatura de $18^{\circ} \mathrm{C}$, acrescidas de 2 horas prévias na temperatura ambiente, de cerca de $25^{\circ} \mathrm{C}$. A exposição à água gelada $\left(0^{\circ} \mathrm{C}\right)$ foi testada durante $20 ; 41$ e 48 horas, enquanto no tratamento com colchicina a $1 \%$, as raízes foram expostas por $5 ; 10$ e 22 horas. Os ápices de raízes foram fixados em solução fresca de Carnoy, etanol e ácido acético glacial 3:1 (v/v). Para a preparação das lâminas, as raízes foram lavadas com água destilada por três vezes seguidas, com duração de dez minutos cada lavagem. Após este procedimento, foram transferidas para um recipiente contendo solução enzimática, constituída por pectinase a $20 \%(\mathrm{v} / \mathrm{v})$ e celulase a $2 \%(\mathrm{p} / \mathrm{v})$ em tampão citrato-fosfato ( $\mathrm{pH} 4,8)$, e mantidas em estufa a $37^{\circ} \mathrm{C}$ por 30 minutos. Os meristemas radiculares foram dilacerados com o auxílio de agulha histológica em ácido acético a $45 \%$ sob um estereomicroscópio. Foi colocada uma lamínula sobre a lâmina e ambas passaram por um breve aquecimento, seguido de uma leve pressão para facilitar a lise celular. Imediatamente após, as lamínulas foram retiradas das lâminas através de congelamento rápido em nitrogênio líquido e secas à temperatura ambiente. Após a secagem, as lâminas foram coradas em solução de Giemsa a $2 \%$ (Guerra \& Souza, 2002). Para a conversão em material permanente, foi utilizado Entelan ${ }^{\circledR}$.

A observação do material foi realizada em microscópio Olympus BX51 com máquina fotográfica acoplada em aumento de $1.000 x$. Para a contagem dos cromossomos, 25 células com bom espalhamento cromossômico foram analisadas. A mensuração cromossômica foi efetuada utilizando-se de, no mínimo, três metáfases fotomicrografadas de cada população. Os comprimentos cromossômicos totais médios e seus respectivos desvios-padrão foram calculados no programa Excel $^{\circledR}$.
A morfologia cromossômica foi descrita segundo Guerra (1986), em cromossomos metacêntricos, submetacêntricos, acrocêntricos e telocêntricos, quando a razão entre os braços cromossômicos (braço longo/braço curto) variou entre 1 a 1,49; 1,5 a 2,99; 3 a $\infty ; \infty$; e quando o índice centromérico (braço curto x 100 /comprimento total) variou entre 40,1 a $50 ; 25,1$ a $40 ; 0,01$ a $25 ; 0 ;$ respectivamente.

\section{RESULTADOS E DISCUSSÃO}

O melhor pré-tratamento foi o uso de água gelada a $0^{\circ} \mathrm{C}$, durante 41 horas. Neste tratamento, foram obtidas muitas pró-metáfases e algumas metáfases com bom espalhamento que, apesar da baixa frequência, puderam ser analisadas morfologicamente. Os outros prétratamentos apresentaram algumas células com fuso cromossômico despolimerizado, entretanto as taxas foram muito baixas.

Todas as espécies estudadas apresentaram o mesmo número cromossômico em células somáticas, $2 \mathrm{n}=2 \mathrm{x}=32$ (Figura 1A-E), apresentaram também a mesma fórmula cariotípica: 14 cromossomos metacêntricos, 12 submetacêntricos e 6 acrocêntricos (Tabela 2). Os cariótipos de todas as espécies foram simétricos, com dois pares de cromossomos satelitados: um par de cromossomos metacêntricos e um de submetacêntricos, ambos com satélites pequenos. Estes cromossomos satelitados parecem manter a mesma estrutura morfológica em todas as populações e espécies estudadas, não possuindo significado taxonômico diferente do que ocorre em Arachis, onde a morfologia dos cromossomos satelitados é característica importante e muitas vezes discriminativa para a seção (Peñaloza, 2006). Esta observação revela que Butia é um grupo homogêneo do ponto de vista cariológico. Esta constância no número cromossômico, observada nas espécies analisadas, indica que mudanças numéricas não têm sido importantes na evolução das espécies de Butia, concordando com o que ocorre na maioria das espécies de Arecaceae (Röser, 1994), o que também ocorre em Rhopalostylis, onde todas as espécies apresentam $2 \mathrm{n}=2 \mathrm{x}=32$ (Lange \& Murray, 2002). A ausência de grandes modificações estruturais encontradas entre as espécies sugere que a morfologia dos cromossomos pode ter contribuído muito pouco para a diversificação do gênero; além disso, o pequeno tamanho dos cromossomos pode dificultar a visualização de modificações estruturais de menor escala.

Arecaceae, aparentemente, tem um número cromossômico básico de $\mathrm{x}=18$ (Moore \& Uhl, 1973), julgando pela sua presença em palmeiras das 
subfamílias Coryphoideae, Phenicoideae, alguns gêneros de Arecoideae e de Borassoideae, sendo que estas subfamílias compartilham características plesiomórficas. Contudo, números cromossômicos reduzidos são facilmente encontrados, formando muitas linhagens de números cromossômicos básicos originados por disploidias decrescentes, como $\mathrm{x}=17$, de ampla ocorrência, sendo $x=16 ; 14$ e 13, também representativos (Raven, 1975). No entanto, ainda há muito a se pesquisar, pois devido ao pequeno número de espécies com descrição citológica ou cariológica, em decorrência dos poucos trabalhos que têm sido realizados neste sentido, pouco se pode inferir sobre os mecanismos envolvidos na evolução cromossômica em Arecaceae.

O gênero Butia, atualmente é incluído em Arecoideae, uma grande e morfologicamente diversa subfamília, onde os números cromossômicos de diversos gêneros geralmente demonstram uma variação entre $2 n=28$ e $2 n=36$, embora os números mais comuns sejam $2 \mathrm{n}=32$ e $2 \mathrm{n}=34$ (Röser, 1994).

Estudos cariomorfológicos caracterizam a disposição da cromatina no núcleo interfásico e são de grande relevância em estudos citotaxonômicos. Segundo Röser (1994), em Arecoideae, os núcleos interfásicos são semirreticulados e caracterizam-se pela variação no formato dos cromocentros, que são originados no final da intérfase, pela condensação da heterocromatina, formando estruturas cromatínicas fortemente pigmentadas de contorno irregular.Este comportamento também foi encontrado nas espécies analisadas no presente trabalho.
Syagrus romanzoffiana possui $2 \mathrm{n}=2 \mathrm{x}=32$ cromossomos (Môro et al., 1999), e esta espécie parece ser geneticamente próxima ao gênero Butia, visto que há registros de cruzamento com várias espécies de Butia, originando um híbrido denominado Butyagrus nabonnandii. Embora todos os híbridos até hoje encontrados sejam estéreis, estes ocorrem com relativa frequência na natureza, em regiões onde estas espécies são simpátricas (Rossato, 2007). Além disso, vários híbridos artificiais têm sido descritos dentro da tribo Butiinae, assim como os obtidos pelo cruzamento Butia X Jubea, cujos híbridos F1 e F2 [(Butia X Jubea) X Butia] são férteis (Wilcox, 2008).

Os números cromossômicos e as fórmulas cariotípicas das espécies de Butia analisadas neste trabalho, em geral, seguem o padrão citogenético descrito para a maioria das espécies de Arecaceae e, em vista das evidências acima apresentadas, demonstram que o número básico do gênero Butia deve ser $\mathrm{x}=\mathrm{n}=$ 16. Contudo, visto que todas as espécies apresentaram o mesmo número cromossômico somático e a mesma fórmula cariotípica, no futuro, maiores estudos serão necessários para o entendimento dos mecanismos evolutivos envolvidos neste processo, principalmente em relação ao posicionamento de blocos cromatínicos de constituição molecular diferenciada no genoma (heterocromatina constitutiva), pelo uso de bandeamento cromossômico convencional (bandas C, NOR) ou por hibridização molecular.

TABELA 1 - Informações dos espécimes, número de tombo das exsicatas das matrizes no Herbário da Universidade de Caxias do Sul (HUCS) ou códigos dos acessos no Banco Ativo de Germoplasma do Laboratório de Óleos Essenciais da Universidade de Caxias do Sul (BAG/ LOES), local de coleta e número de plantas analisadas em oito populações de cinco espécies de Butia.

\begin{tabular}{cccc}
\hline Espécie & Código identificador & Origem & $\mathbf{N}^{\mathbf{0}}$ de plantas \\
\hline Butia capitata & HUCS 24800 & Lavras do Sul & 1 \\
& HUCS 24604 & Caxias do Sul & 2 \\
& BAG/LOES 0024 & Ipê & 3 \\
& HUCS 24802 & Santa Vitória do & 3 \\
B. eriospatha & HUCS 27994 & Palmar & 3 \\
B. odorata & HUCS 27995 & Torres & 3 \\
B. paraguayensisana & São Francisco de & 2 \\
B. yatay & HUCS 27927, HUCS & Assis & 2 \\
\hline
\end{tabular}


TABELA 2 - Vores médios $(\mu \mathrm{m})$ das medidas do comprimento total dos cromossomos de Butia. Complemento haploide total (CHT), razão média entre os braços cromossômicos (L/C), índice centromérico médio (IC), comprimento médio do cromossomo mais curto (CMCC), comprimento médio do cromossomo mais longo (CMCL) e comprimento cromossômico médio (CCM).

\begin{tabular}{ccccccccc}
\hline Espécies & 2n & Cariótipo & CHT & L/C & IC & CMCC & CMCL & CCM \\
\hline Butia capitata & 32 & $14 \mathrm{~m}+12 \mathrm{sm}+6 \mathrm{a}$ & 32,76 & 1,97 & 31,37 & 1,11 & 2,90 & 2,05 \\
B. eriospatha & 32 & $14 \mathrm{~m}+12 \mathrm{sm}+6 \mathrm{a}$ & 33,05 & 2,01 & 37,32 & 1,60 & 3,44 & 2,07 \\
B. odorata & 32 & $14 \mathrm{~m}+12 \mathrm{sm}+6 \mathrm{a}$ & 37,83 & 1,97 & 37,01 & 1,32 & 2,97 & 2,36 \\
B. paraguayensis & 32 & $14 \mathrm{~m}+12 \mathrm{sm}+6 \mathrm{a}$ & 32,21 & 1,94 & 37,23 & 1,32 & 2,68 & 2,01 \\
B. yatay & 32 & $14 \mathrm{~m}+12 \mathrm{sm}+6 \mathrm{a}$ & 33,41 & 1,92 & 37,86 & 1,40 & 2,88 & 2,09 \\
\hline
\end{tabular}

$\mathrm{m}=$ metacêntrico, $\mathrm{sm}=$ submetacêntrico e $\mathrm{a}=$ acrocêntrico
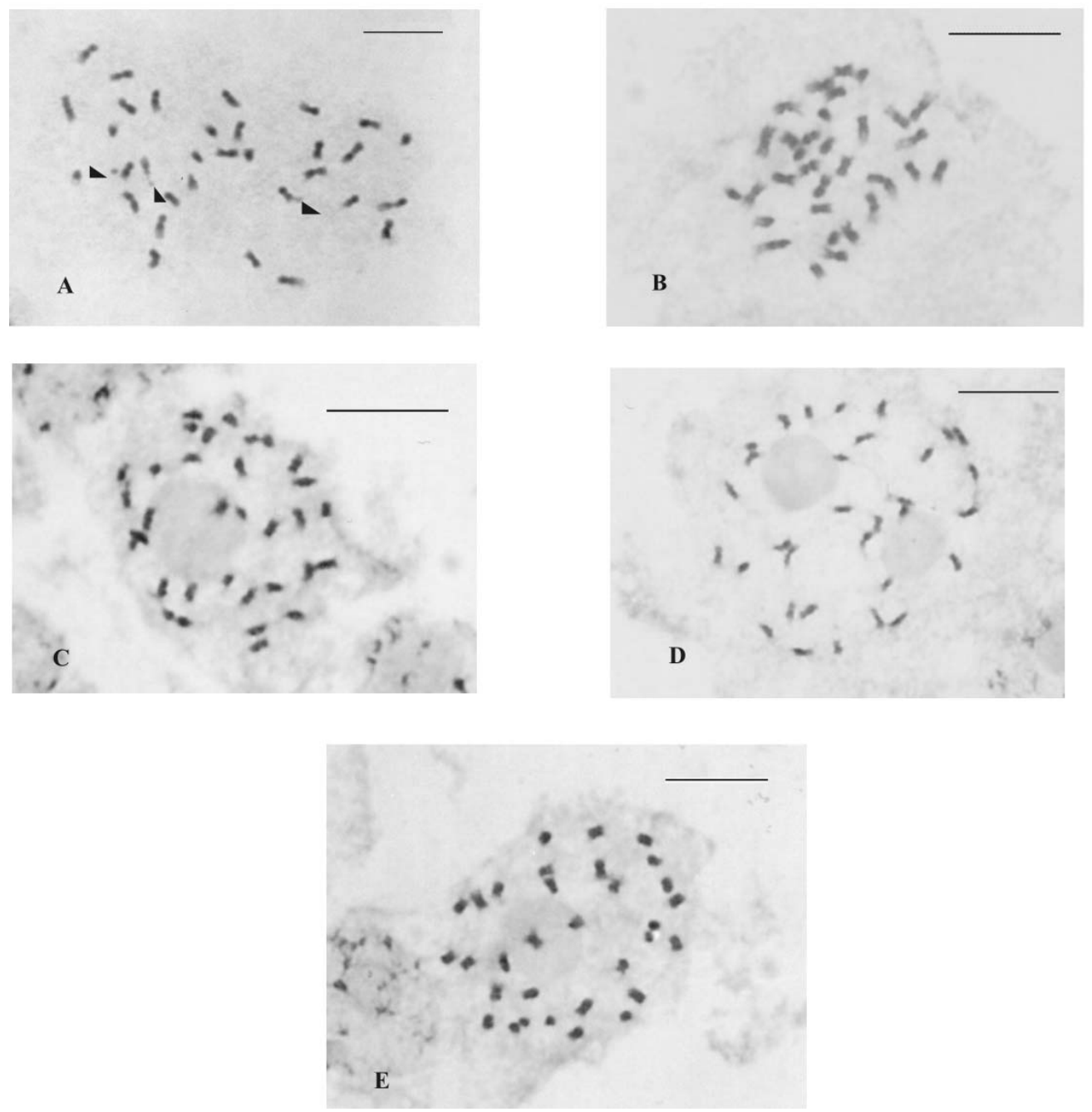

FIGURA 1 - Complemento cromossômico somático de espécies de Butia, todas as células apresentando 2n $=2 \mathrm{x}=32$ cromossomos. A. B. capitata, B. B. odorata, C. B. eriospatha, D. B. paraguayensis e E. B. yatay. Escalas correspondem a $10 \mu \mathrm{m}$, e as setas indicam os satélites cromossômicos. 


\section{REFERÊNCIAS}

ANGIOSPERM PHYLOGENY WEBSITE. APG II, Angiosperm Phylogeny Group System II. Disponível em: < http://www.mobot.org/MOBOT/research/ APweb/welcome.html >. Acesso em: 02 jul. 2008.

CLEMENT, C. R. Melhoramento de espécies nativas. In: NASS, L. L.; VALOIS, A. C. C.; MELO, I. S.; VALADARES-INGLIS, M. C. Recursos genéticos \& melhoramento de plantas. Rondonópolis: Fundação de Apoio à Pesquisa Agropecuária de Mato Grosso, 2001. p. 423-441.

DRANSFIELD, J.; UHL N.W. Genera Palmarum: a classification of palms based on the work of Herald E. Lawrence: Moore Jr. Allen Press, 1987. 610p.

GAIERO, P.; MAZZELLA, C. Las palmas (Arecaceae) en Uruguay: analisis cromosomico en especies nativas de Butia, Syagrus y Trithrinax. In: SIMPÓSIO DE RECURSOS GENETICOS PARA AMÉRICA LATINA Y EL CARIBE, 5., 2005, Montevideo. Anais... p.57.

GOLDBLATT, P. Polyploidy in angiosperms: monocotyledons. In: LEWIS, W.H. (Ed.) Polyploidy: biological relevance. New York: Plenum Press, 1980. p.219-239.

GUERRA, M. Citogenética de Angiospermas coletadas em Pernambuco I. Revista Brasileira de Genética, Porto Alegre, v.9, p.21-40, 1986.

GUERRA, M.; SOUZA, M.J. Como observar cromossomos: um guia de técnica em citogenética vegetal, animal e humana. Ribeirão Preto: Ed. Funpec, 2002. 131p.

HENDERSON, A.; GALEANO, G.; BERNAL, R. Field guide to the palms of the Americas. Princeton: Princeton University Press, 1995. 352p.

LANGE, P.J.; MURRAY, B.G. Contributions to a chromosome atlas of the New Zealand flora - 37. Miscellaneous families. New Zealand Journal of Botany, Wellington, v.40, p.1-23, 2002.

MARCATO, A.C. Revisão taxonômica do gênero Butia (Becc.) Becc. e filogenia da subtribo Butiinae Saakov (Palmae). 2004. 147 f. Tese (Doutorado) Universidade de São Paulo, São Paulo, 2004.

MOORE, H.E.; UHL, N.W. Palms and the origin and evolution of monocotyledons. The Quarterly Review of Biology, Chicago, v.48, p.414-436, 1973.

MÔRO, J.R.; SILVA, M.A.S.; GERALDO, J.S. Methodology for kariological study of brazilian palms. Acta Horticulturae, Leuven, v.486, p.225228, 1999.

PEÑALOZA, A.P.S. Citogenética e citotaxonomia do gênero Arachis I: importância e avanços recentes. In: Mariath, E.A.; Santos, R.P. Os avanços da Botânica no início do século XXI. Gramado: Ed. Sociedade Botânica do Brasil, 2006. p.142-146.

PNDU, Programa das Nações Unidas para o desenvolvimento. MG insere produtos nativos no mercado. Disponível em: <http://www. pnud.org.br/meioambiente/reportagens/index. php?id01=481\&lay=mam $>$. Acesso em: 25 nov. 2007.

RAVEN, P.H. The Bases of Angiosperm Phylogeny: Cytology. Annals of the Missouri Botanical Garden, St. Louis, v.62, p.724-764, 1975.

READ, R.W. Chromosome numbers in the Coryphoideae. Cytologia, Tokyo, v.30, p.385-391, 1965.

READ, R.W. New Chromosome counts in palms. Principes, Lawrence, v.28, p.20-30, 1966.

RIVAS, M.; BARILANI, A. Diversidad, potencial productivo y reproductivo de los palmares de Butia capitata (Mart.) Becc. de Uruguay. Agrociencia, México, v.3, p.11-21, 2004.

RÖSER, M. Pathways of karyological differentiation in palms (Arecaceae). Plant Systematics and Evolution, Viena, v.189, p.83-122, 1994.

ROSSATO, M. Recursos Genéticos de Palmeiras Nativas do Gênero Butia do Rio Grande do Sul. 2007. 136f. Tese (Doutorado) - Universidade Federal de Pelotas, Pelotas, 2007.

SINGH, D.N. Use of induced rooting in cytological studies. Nature, Londres, v.169, p.420-421, 1961.

WILCOX, M. Practical methods for hybridization in the Butiinae. Disponível em: <http://www. plantapalm.com/vpe/horticulture/vpe_horticulture5. htm>. Acesso em: 16 maio 2008. 